\title{
Geosemiotic Analysis of Signs in the Linguistic Cityscape of China
}

\author{
Jing Jing Wang \\ College of Languages and Culture, Northwest A\&F University, Xianyang, China
}

Email address:

nancy_wjj@hotmail.com

\section{To cite this article:}

Jing Jing Wang. Geosemiotic Analysis of Signs in the Linguistic Cityscape of China. International Journal of Language and Linguistics. Vol. 9, No. 4, 2021, pp. 226-232. doi: 10.11648/j.ijl1.20210904.23

Received: July 15, 2021; Accepted: August 10, 2021; Published: August 23, 2021

\begin{abstract}
In the last several decades, adding English to public signboards has become a common phenomenon in China, and the inclusion of more foreign languages other than English for a sign in public sphere has drawn much attention in recent years. In sociolinguistic research, linguistic landscape is a more common term and has been adopted most in studies worldwide which always target at languages used in city centers as a tradition. This study is an attempt to investigate multilingualism in the public sphere of China. Focusing on the linguistic landscape of Xi'an, an ancient city of China, it explores the visibility and salience of languages used on signboards in the city center under the theoretical framework of Geosemiotics. The Geosemiotic analysis demonstrates that Chinese-English bilingual signs constitute about half of the linguistic cityscape of Xi'an; trilingual signs on commercial signboards often carry incoordinate information in different languages; for quadrilingual signs, a relatively fixed order is given to different languages. Besides, the display of traditional Chinese characters on signboards in the cityscape often appear on the wooden plates, which create an "ancient" feeling to visitors. This research also indicates that there is a tendency to standardize the display of language signs in the public sphere of Xi'an city, despite that the desire to be internationalized had been emphasized a lot by many researchers in early studies on linguistic landscape worldwide.
\end{abstract}

Keywords: Linguistic Landscape, Geosemiotics, Public Visibility, Multilingualism, China

\section{Introduction}

Language signs are everywhere around us, and resorting to street signs, shop signs, and notices in public space are part of our daily life. In recent years, linguistic landscape has become a popular methodological approach to observe language usage in a certain area or region, and researchers from diverse disciplinary backgrounds focus not only on languages, but also on the change of society $[1,9]$. In sociolinguistic research, linguistic landscape is the most frequently quoted term, which includes languages used on both "public and commercial signs in a given territory or region" [16]. In addition, cities and towns in particular, which show the highest density of signs that exposed in shopping streets, commercial and industrial areas [5, 18, 25], have been the focus of linguistic landscape research to observe the interaction of different cultures, languages and identities. Thus, the present research adopts the term "linguistic cityscape" put forward by Spolsky [23] who emphasizes that the topic of interest of linguistic landscape research is public sign in urban space and the notion of urban linguistic landscape, which is drawing much attention from scholars in China as well in the last few years. Based on a survey on the languages used on signboards in the city center of Xi'an, an ancient city and famous tourist attraction in China, this study will extend the definition for linguistic landscape given by Landry and Bourhis [16] by examining and analyzing street and road names, place and building nameplates, shop signs, advertising billboards, informing signs, directing signs, prompting signs, warning signs and slogans in this urban setting.

Drawing on Scollon and Scollon's [21] framework of Geosemiotics, this study will analyze the formation of different types of signs to understand how the linguistic landscape of this ancient city is constructed, thus contributes to the existing research in the linguistic landscape in China, and to some degree shed some light on the linguistic landscape research worldwide. It is worthwhile to point out though that linguistic landscape does not rise as a new research topic until recent years in China, that many early 
studies investigated the use of English in public signs, with a focus on the English translation of Chinese-English bilingual signs. So far, multilingualism in the urban setting, an underresearched topic, is still a relatively new field to explore in China. Focusing on the city center of Xi'an where the linguistic landscape expresses most clearly its multilingualism, this research is of great importance to understand linguistic landscape in a different region and provides useful insight as to in what way changes are going on in the linguistic cityscape of China.

\section{Research Site}

The current study surveys the urban space of Xi'an, the capital city of Shaanxi Province of China. Xi'an is one of the oldest cities in China, also known as the oldest of the Four Great Ancient Capitals of the world, and one of China's most popular tourist destinations because of its ancient cultural heritage that attracts visitors worldwide. In addition, with the release of the "Belt and Road" Initiative proposed by the Chinese government in 2013, Xi' an, as the starting point of the new Silk Road Economic Belt, plans to seize this chance and transform itself into an international city, although it is already the most industrialized city in the northwest of China. According to the statistical bulletin on national economic and social development of Xi' an City released in 2019, Xi'an has received over 247 million tourists from home and abroad in 2018. Moreover, the tourism economic development report of Shaanxi Province indicates that among the 4.4 million foreign visitors, about $18 \%$ are from Korea, $13 \%$ from America, 5\% from Malay, with visitors from Japan, British, Australia, France, Germany, Canada, Italy, constituting the majority of foreign tourists.

\section{Data Collection}

Signs in this study were collected from four main streets in the city center of Xi'an, namely, East Street, South Street, West Street and North Street, meeting in Bell Tower, the landmark, also the geographical center of the ancient capital, with a small square next to it and an underground roundabout. A total of 874 signs are photographed by digital camera, and further classified as street and road names, place and building nameplates, shop signs, advertising billboards, informing signs, directing signs, prompting signs, warning signs and slogans, which can be obviously observed in side streets by passers-by. Specifically, signs in a relatively stable position and bigger size (no less than $40 \mathrm{~cm}$ in length and $30 \mathrm{~cm}$ in width), which can be spatially identified as a separate sign or unit of analysis are photographed for the current study, because these signs are not replaced quickly, such as inscriptions on wooden plaque, nameplates for normally open shops, and advertising boards fixed on the wall of shopping malls. In other words, temporarily erected advertising posters, paper notices and electronic screens on storefront and display window are excluded from the current research.

\section{Framework of Geosemiotics}

The term 'geosemiotics', defined as the study of 'discourses in place' by Ron Scollon and Suzie Wong Scollon [21], deals with the social meanings of the material placement of signs and discourses in the material world. Focusing on the relationship between language and place from the perspective of Semiotics, it aims to study the meaning system that enables language to be combined with the material world. As Scollons suggested, the meaning of the text or language displayed in public places cannot be interpreted without associating it with the social and physical environment they are located. Combining sociocultural theory, semiotic theory, and ethnographic studies of signs, they illustrate how the physical/material characteristics of language form meaning to communications and how those meanings differ from place to place in the world.

In their book Discourse in Place: Language in the Material World, three broad aspects - interaction order, visual semiotics and place semiotics - are incorporated in to the framework of Geosemiotcs. The current study will mainly emphasize 'place semiotics' of public signs in the city center of Xi'an city of China, which is the central thesis of Scollons' work that presents the analysis systems of code preference, inscription and emplacement, and visual semiotics that looks at the ways in which pictures, including signs, images, text, photographs and so on, are produced as meaningful wholes for visual interpretation [21].

\section{Geosemiotic Analysis of Language Signs in the Cityscape of Xi'an}

\subsection{Languages Displayed in Cityscape}

Blommaert [3] indicates that linguistic landscape is 'a first-line sociolinguistic diagnostic of particular areas' and 'offers the fieldworker a relatively user-friendly toolkit for detecting the major features of sociolinguistics regimes in an area: monolingual or multilingual?' The field survey of signs in the linguistic cityscape of Xi'an shows that $48.4 \%$ of them are monolingual, $48.9 \%$ bilingual, $1.4 \%$ trilingual, $1 \%$ quadrilingual and several signs use symbols only (see Table 1). In terms of linguistic representation, Chinese is displayed as the most frequently used language, appearing in $85 \%$ signs, while English featured in $62 \%$ signs. In addition, more than half $(51 \%)$ of the signs are bilingual or multilingual, in which Chinese-English signs account for $98 \%$ of the bilingual signs. As we expected, Chinese (72.6\%) constitute the majority of monolingual signs, and English is the most preferred foreign language. Other foreign languages such as Japanese, Korean, French, Italian and German, also show their frequent appearance in the cityscape of Xi'an. As a famous tourist attraction in China, one primary purpose of erecting an English sign in this city is to offer service and convenience to travelers, which can be proved by the large number of Chinese-English bilingual signboards carrying informing, directing, prompting and warning information in the public 
sphere, although the presence of English is often taken as an index of internationalization by researchers worldwide [7, 14, $18,20,24]$. Moreover, the pervasive use of foreign languages is found at South Street, where we can observe many monolingual nameplates in languages such as French, German and Italian, inscribed on the outside wall of big shopping malls. Besides, in some cases of multilingual signs, foreign languages may even take a more prominent position on a nameplate, as shown in Figure 1, a nameplate for a chain store of a Korean coffee company. The name caffè bene in Italian is put in the center of the signboard, with Korean, Chinese and English displayed around it carrying incoordinate information, which is pertinent to code preference in geosemiotics, to which I will turn next.

Table 1. Signs by the number of languages displayed at the four streets of Xi'an City.

\begin{tabular}{|c|c|c|c|c|c|c|c|c|}
\hline \multirow{2}{*}{ Street Names } & \multicolumn{8}{|c|}{ Number of Different Types of Signs } \\
\hline & Monolingual & Bili & & Tri & & Quadrilingual & Sy & Only \\
\hline East Street & 86 & 108 & & 1 & & 0 & 1 & \\
\hline South Street & 62 & 51 & & 2 & & 0 & 0 & \\
\hline West Street & 159 & 169 & & 6 & & 6 & 2 & \\
\hline North Street & 114 & 99 & & 3 & & 3 & 0 & \\
\hline Total: 874 & $48.4 \%$ & 427 & $48.9 \%$ & 12 & $1.4 \%$ & $1 \%$ & 3 & $0.3 \%$ \\
\hline
\end{tabular}

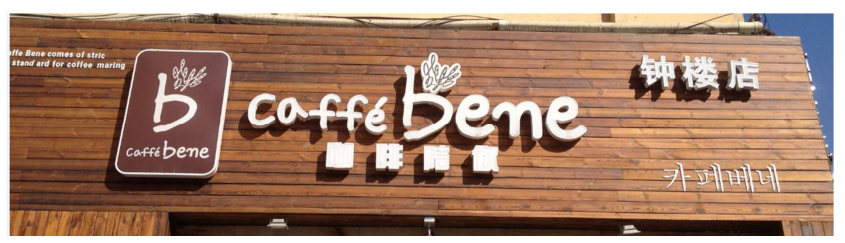

Figure 1. Caffè bene coffee shop, West Street, Xi'an.

\subsection{Code Preference}

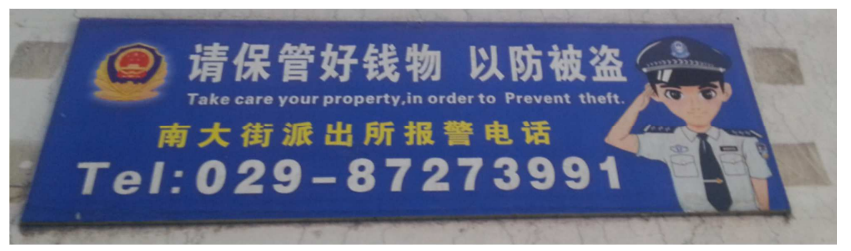

Figure 2. Prompting sign in the underground roundabout of the Bell Tower, Xi'an.

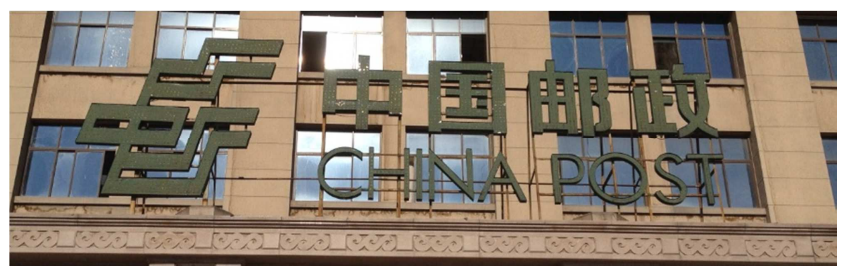

Figure 3. Post office of China Post, East Street, Xi'an.

As shown in Table 2, Chinese-English bilingual signs (93\%) constitute the majority of bilingual and multilingual signs, which can be observed in both public signboards where Chinese is often put in a preferred position either by displaying above English or in a larger size (see Figure 2 and Figure 3), and private signboards, where the priority is often given to English. In addition, the combination of Chinese and other foreign languages in bilingual and trilingual signs are most found in commercial signs, which tend to show the degraded role of Chinese by putting foreign languages in a prominent position or in a special design that attract more attention from passers-by, which fulfills the symbolic function of foreign languages [16]. However, it was interesting to witness that the role of Chinese is strengthened again in quadrilingual signboards, most in public signs collected in this study. As could be seen in Figure 4, the inscription on the stone fixed on the wall leaves a permanent impression on its readers. The visually prominent position of Chinese, and less preferred position given to English, Korean and Japanese accordingly is the common order for quadrilingual signs found in this study, although the position of Korean and Japanese is often exchanged in some cases.

Scollon and Scollon [21] indicate that 'When a text is in multiple codes (two or three more languages such as English and Chinese) or multiple orthographies there is a system of preference and usually a choice system is formed. Further, they explained that the preferred position is 'on top, on the left, or in the center and the marginalized code is on the bottom, on the right, or on the margins.' In this study, closer observation is made in order to understand the salience of language in Xi'an through code preference. In the current study, it is found that over $50 \%$ signs display Chinese with English, which signifies a strong desire to include English into the signboard, although the prominent and more visible position is always given to Chinese (about 92\%). In addition, it is worthwhile to mention that English is not always used as an index of a modern city. In other words, their informational function is emphasized more than symbolic function, as proved by the large number of bilingual public signs in Chinese and English, in which English is usually targeted at helping foreigner who cannot read Chinese, which further indicates that the language 'can be used to communicate and obtain services within public and private establishments located in the pertinent territory' [16]. As could be seen in Figure 2, the Chinese sentence on the top of the signboard, which provides key information, attracts the readers' attention first, and with the police image, its importance was further highlighted, while the English version of this sentence is given below in smaller size providing equivalent information. This is a common pattern showing priority in the composition of Chinese-English bilingual signs, and English here is mainly adopted to fulfill the informational function, although it also symbolizes the existence of foreign visitors who can read English in this city. 


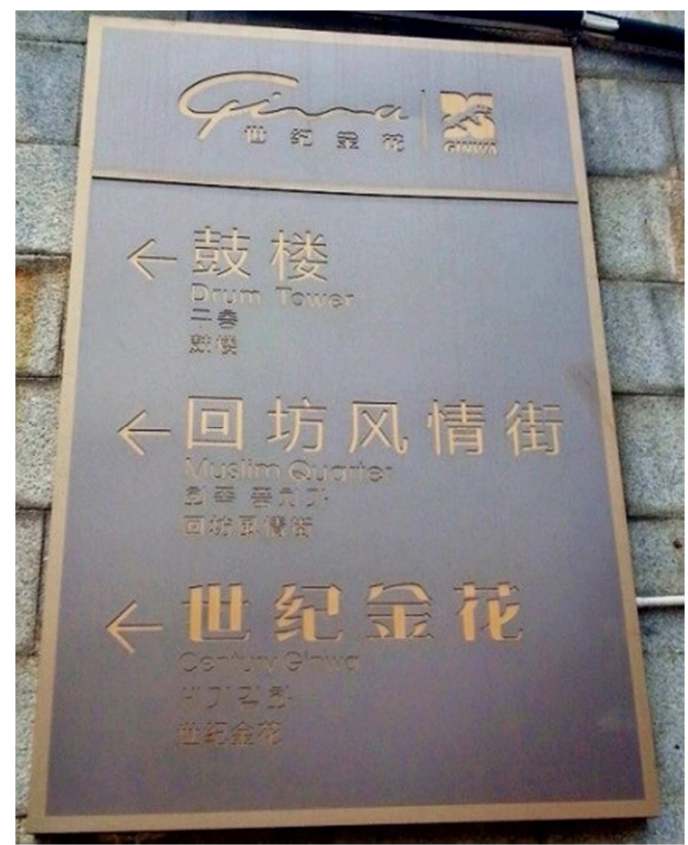

Figure 4. Quadrilingual nameplate, North Street, Xi'an.
Table 2. Languages used in bilingual and multilingual signs in the cityscape of Xi'an.

\begin{tabular}{llll}
\hline Type of Sign & Languages Used & No. & Percentage \\
\hline \multirow{4}{*}{ Bilingual } & Chinese+English & 416 & $93 \%$ \\
& Chinese+Korean & 5 & $1.1 \%$ \\
& Chinese+Arabic & 4 & $0.9 \%$ \\
& English+Japanese & 2 & $0.4 \%$ \\
\multirow{5}{*}{ Trilingual } & Chinese+English+Japanese & 3 & $0.7 \%$ \\
& Chinese+English+Korean & 5 & $1.1 \%$ \\
& Chinese+English+Arabic & 6 & $1.3 \%$ \\
Quadrilingual & Chinese+English+Japanese+Korean & 9 & $2 \%$ \\
Total & Chinese+English+Korean+Italian & 1 & $0 \%$ \\
\hline
\end{tabular}

Under the influence of globalization, public sphere tends to be absorbed by the commercial sector [8]. Table 3 provides a classification of different types of signs, showing that shop signs $(74.7 \%)$ compose the majority of the cityscape, and informing signboard and advertising billboards follow. It needs to be noted that all the slogans are presented in Chinese (See Figure 5), and all the trilingual signs are found in the shop domain, while quadrilingual signs are mainly found in place names and informing signs.

Table 3. Different types of signboards and their percentage.

\begin{tabular}{|c|c|c|c|c|c|c|c|c|c|c|}
\hline \multirow{2}{*}{ Type of sign } & \multicolumn{2}{|c|}{ Monolingual } & \multicolumn{2}{|c|}{ Bilingual } & \multicolumn{2}{|c|}{ Trilingual } & \multicolumn{2}{|c|}{ Quadrilingual } & \multicolumn{2}{|c|}{ Total } \\
\hline & $\mathbf{N}$ & $\%$ & $\mathbf{N}$ & $\%$ & $\mathbf{N}$ & $\%$ & $\mathbf{N}$ & $\%$ & $\mathbf{N}$ & $\%$ \\
\hline Street/road names & 1 & 0.2 & 12 & 2.8 & 0 & 0 & 0 & 22.2 & 15 & 1.7 \\
\hline Building /place names & 26 & 6.1 & 17 & 2.0 & 0 & 0 & 3 & 0 & 43 & 4.9 \\
\hline Advertising billboards & 37 & 8.7 & 26 & 6.3 & 0 & 0 & 1 & 0 & 64 & 7.3 \\
\hline Informing/Directing & 28 & 6.6 & 44 & 10.3 & 0 & 0 & 6 & 0 & 72 & 8.3 \\
\hline Prompting & 3 & 0.7 & 4 & 0.9 & 0 & 0 & 0 & 0 & 7 & 0.8 \\
\hline Slogans & 7 & 1.7 & 0 & 0 & 0 & 0 & 0 & 0 & 7 & 0.8 \\
\hline Total & 423 & $48.6 \%$ & 427 & $49.0 \%$ & 12 & $1.4 \%$ & 9 & $1.0 \%$ & 871 & $100.0 \%$ \\
\hline
\end{tabular}

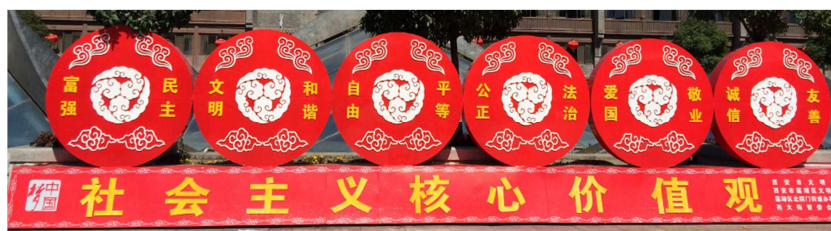

Figure 5. Slogan (the core Socialist values) in West Street, Xi'an.

\subsection{Arrangement of Bilingual and Multilingual Text}

Reh [19] provides a model that describes the relationship between message content and languages adopted on signboards, and categorizes the multilingual writing into four types: (1) duplicating multilingual writing: same information given in different languages (2) fragmentary multilingual writing: full information provided in one language with partial information translated into other languages (3) overlapping multilingual writing: complete information given in one more languages with partial information in only one language; and (4) complementary multilingual writing: full information translated into different languages. Because of the complexity of information contained in signs, overlapping and fragmentary messages are taken as one type of signs in the current study, as Table 4 summarized. Figure 1 exemplifies overlapping information in quadrilingual signboard, where main information is given in Italian and additional information in Chinese, Korean and English, and this type of signs constitutes $34.6 \%$ of the cityscape. Besides, it is found that 245 of 448 bilingual and multilingual signs (53.6\%) display equivalent information (duplicating type) in different languages.

Table 4. Types of text arrangement in bilingual and multilingual signs.

\begin{tabular}{|c|c|c|c|c|}
\hline Type of Sign & Duplicating & & Fragmentary/ Overlapping & Complementary \\
\hline Bilingual $(n=427)$ & 231 & & 150 & 46 \\
\hline Multilingual $(\mathrm{n}=21)$ & 14 & & 5 & 2 \\
\hline Total $(n=448)$ & 245 & $53.6 \%$ & $34.6 \%$ & $10.7 \%$ \\
\hline
\end{tabular}




\subsection{Inscription}

\subsubsection{Text \& Image}

Shohamy and Gorter [22] point out that the center of attention in linguistic landscape research is language, words and images displayed in public spaces. In contrast, Gorter \& Cenoz [13] indicate that linguistic landscape research focuses on analyzing the written information in a specific area. Thus, the question of whether visual data (images and other multimodal literacies) should be included into the analysis of linguistic landscape is still under debate. In practice, signboards often include images or other graphic elements as well as text, as Kress and Leeuwen [15] claimed 'language always has to be realized through, and comes in the company of, other semiotic modes.' Moreover, Goddard [12] also stated '...readers do not simply read images in isolation from the verbal text that accompanies them; nor do they read verbal text without reference to accompanying images.' Thus, this study takes both words and images into analysis, a stance held by Shohamy and Gorter [22].

Kress and Leeuwen [15] put forward that semiotic modes interrelate in three different ways, based on which, it can be concluded that the meaning of a visual object is always produced by multiple possible elements related to it, and the interactions of those elements that compose the object as a whole. A close observation of the public signage of Xi'an city demonstrates the complexity in the interaction of text and images or semiotic signs, as shown in Table 5, which shows that more than $40 \%$ of the signs display text with visual aids, such as pictures, images and symbols. Figure 6 is a typical example of multimodal sign, where we can find different shapes, colors, pictures and symbols are incorporated into the map with the written text given in Chinese and English in different sizes respectively.

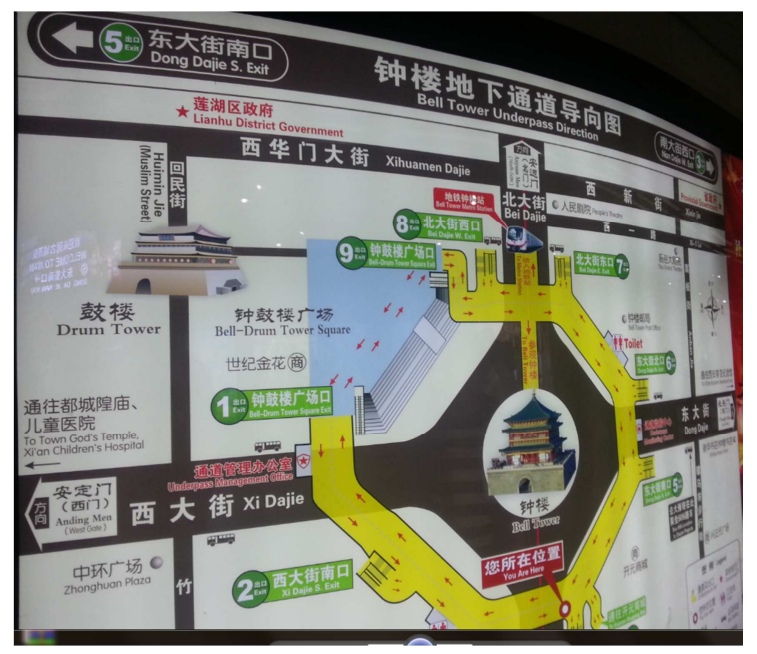

Figure 6. Map in the underground roundabout of Bell Tower, Xi'an.

Table 5. Number of text-only signs and visual data added signs.

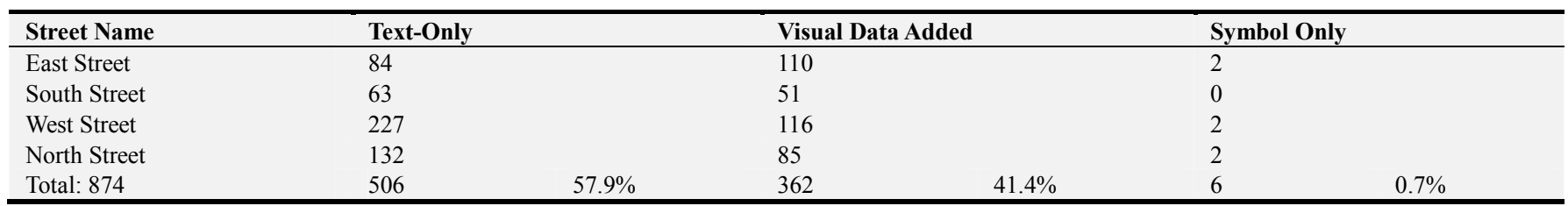

\subsubsection{Material}

In Scollon and Scollon's [21] work, inscription, based on the physical materiality of language, covers all of the meaning systems, including letterform, material, layering and state changes. In this study, I expect that there will be some traditional elements in the design of signboards in this ancient city, and the material of the signboard is the most obvious and direct embodiment. Thus, special attention is given to the material of which signboards are made. According to Scollon and Scollon [21], material refers to 'the physical substance on which the inscription is made'. Based on my observation, wooden plates are widely used by shops, public institutions, agencies, offices of all kinds, especially in the West Street. Figure 7 shows a shop for watch repairing, displaying its name “鐘表修理部” in traditional Chinese characters on a wooden plate, which presents a permanent nature [21]. Furthermore, this nameplate with engraved golden characters and four specially designed corners under the roof of Chinese traditional style also demonstrate that it is a shop offers service of high quality. In similar way, Figure 8 is a nameplate for a famous jewelry store in China, and the same design for its nameplate is applied nationwide. The golden colored traditional Chinese characters on the plate makes it conspicuous on the street. In addition, it needs to be mentioned that these stores usually exclude foreign languages from its nameplate to maintain its uniqueness and Chinese tradition, which further remind the passers-by that they are in an "old" city.

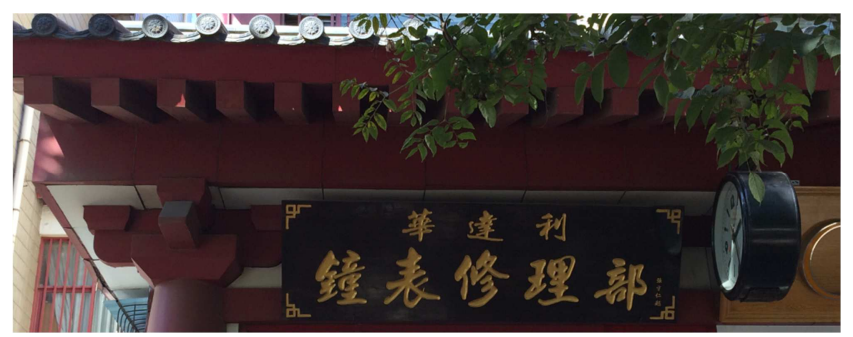

Figure 7. Shop for watch repairing, West Street, Xi'an.

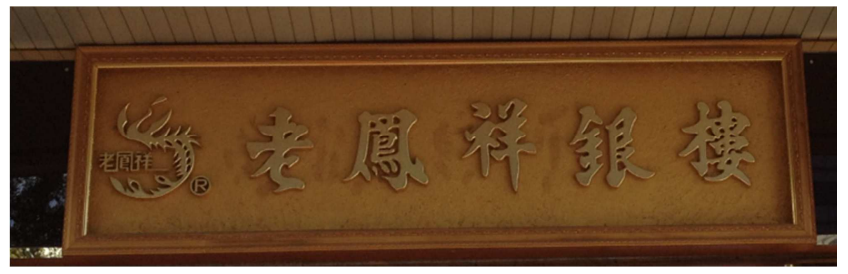

Figure 8. Laofengxiang Jewelry Store, East Street, Xi'an. 


\subsubsection{Emplacement}

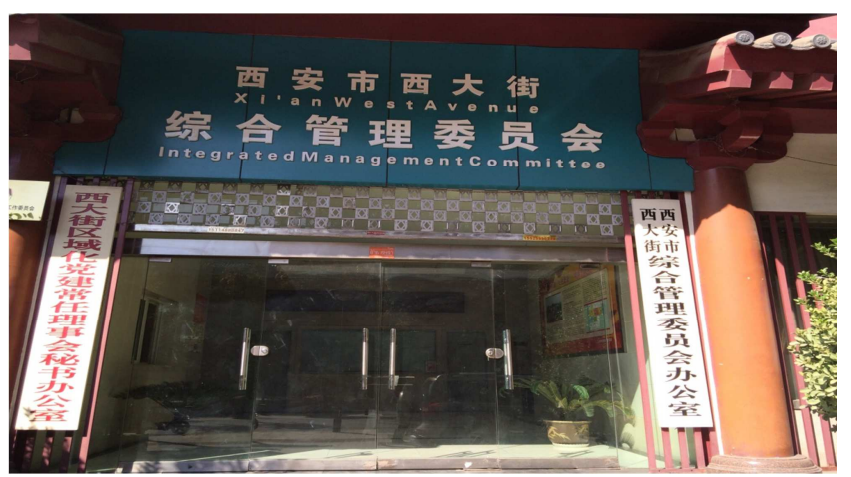

Figure 9. Management Committee of Xi'an West Avenue, West Street, Xi'an.

Scollon and Scollon [21] define emplacement as 'where in the physical world is the sign or image located'. In fact, this is a further investigation on "in what way the texts are situated". In the context of the ancient city of Xi'an, compositional symmetry is an important feature demonstrated by many signboards. As shown in Figure 9, on the top, over the entrance, is the name of the Integrated Management Committee of West Avenue, with wooden couplet fixed at the two sides of the door under its name, which form a pattern of symmetry and provides two more names clarifying the functions of this committee. This pattern of symmetry is a common and popular design at the entrance of buildings in the West Street, which helps create the "ancient" cultural atmosphere of Xi'an, but usually with one side of the couplet missing in some cases, although this is not the most traditional way for displaying a nameplate for a building, as proved by the text vector and simplified Chinese character in the nameplate. In fact, it is the right to left writing that is common in pre-modern China, which is reserved for symbolic use of traditional Chinese culture, and connected with traditional Chinese aesthetics [21]. Therefore, it is necessary to note that in most cases the left to right reading path is the prevalent reading path of text vector in the cityscape of Xi'an.

\section{Conclusion}

In this paper, I adopted the geosemiotic framework put forward by Scollon and Scollon [21] to investigate language usage on signboards in the public space of Xi'an city in China, which gives special attention to urban multilingualism in this traditional and new city that are making efforts to become cosmopolitan, which provided important insights into linguistic landscape research. Bolton [4] points out that linguistic landscape research may "help us to understand the rapidly changing urban landscapes, and the increasingly multilingual worlds, in which we live or experience through travel. For Xi'an city, famous of historical and cultural heritage, tourism development is an important incentive for the promotion of foreign languages in public places, which is also closely related to the national globalization strategies, such as the 'Belt and Road' initiative [11]. Early studies have discussed extensively about the relationship between the process of globalization and the wide use of English [10, 1, 2], and the concept that the pervasive use of foreign languages, especially English, in the city, is an index of being globalized has been taken for granted. This is applied to the linguistic cityscape of Xi'an as well, as the geosemiotic analysis shows that the globalization of the cityscape of Xi'an is first manifested in the form of the global language: English - appearance in $62 \%$ signboards, and then the increasing presence of other foreign languages - appearance in 5\% signboards. In my survey, monolingual signs in foreign languages are adopted most in brand names usually used as shop signs, which testifies the emergence of linguistic diversity in the linguistic cityscape in the last decades as well.

In the cityscape of Xi'an, public signs basically adopted Chinese only or Chinese and English, while other foreign languages were mainly used in commercial signs. On one hand, in the context of this "being cosmopolitanized" city, the mixture of different languages is a result of growing globalization which carries symbolic association; on the other hand, in addition to the usage as names in commercial domain, phrases or lengthy text in English and other foreign languages are also found in public signs, which does not necessarily cause conflict as early studied often noted. Instead, what we can observe is the urgent need for adding foreign languages onto more signboards and the increasing number of multilingual public signboards, which is indicated by the current study through analyzing the coexistence of four languages on public signboards in the city center. Moreover, this trend has come into being under the current management of National Tourism Administration that puts forward standard and request for tourist attractions. Thus, even if we cannot state that Xi'an has become a multilingual city where people from different cultures fused together and form a multi-ethnic community, obviously, it has demonstrated a common multilingual public space, where foreign languages are promoted in the written form, and further stimulate the formation of language policy and regulation at different government levels. And more importantly, it is necessary to mention that copresence and wide use of English and Chinese on official signboards, and increasing quadrilingual public signs are witnessing the process of standardizing the cityscape of Xi'an. Hence, we can observe a more organized and richer linguistic cityscape in this city stepping forward globalization under current developmental strategies of the national and provincial governments. In turn, the globalization process also motivated the wide use of foreign languages in the city center.

\section{Acknowledgements}

This work was supported by Shaanxi Province and Northwest A\&F University [grant number 2015RWYB27; 2013BSJJ104]. 


\section{References}

[1] Backhaus, P. 2007. Linguistic Landscapes: A Comparative Study of Urban Multilingualism in Tokyo. Clevedon, UK: Multilingual Matters.

[2] Ben-Rafael, E., Shohamy, E., Amara, M. H., and N. TrumperHecht. 2006. "Linguistic Landscape as Symbolic Construction of the Public Space: The Case of Israel." International Journal of Multilingualism 3 (1): 7-30.

[3] Blommaert, J. 2013. Ethnography, Superdiversity and Linguistic Landscape: Chronicles of Complexity. Bristol: Multilingual Matters.

[4] Bolton, K. 2012. "World Englishes and Linguistic Landscapes." World Englishes 31: 30-33.

[5] Shohamy, E., Ben-Rafael, E. and Barni, M. 2010. Linguistic Landscape in the City. Bristol, Blue Ridge Summit: Multilingual Matters.

[6] Cenoz, J., and D. Gorter. 2009. Language Economy and Linguistic Landscape. In Linguistic landscape: Expanding the scenery, edited by E. Shohamy, and D. Gorter, 55-69. New York, NY: Routledge.

[7] Dimova, S. 2007. English shop signs in Macedonia. English Today, 23 (3 \& 4). 18-24.

[8] Delanty, G. 2007. Public sphere. In Blackwell Encyclopedia of Sociology, edited by Ritzer, G. Oxford: Blackwell Publishing.

[9] Hasanova, D. 2021. The linguistic landscape of Bukhara and Tashkent in the post-Soviet era. World Englishes, 1-14. https://doi.org/10.1111/weng.12553

[10] Huebner, T. 2006. "Bangkok's Linguistic Landscapes: Environmental Print, Code Mixing, and Language Change." International Journal of Multilingualism 3 (1): 31-51.

[11] Gao, X., and Y. Zheng. 2019. Multilingualism and Higher Education in Greater China. Journal of Multilingual \& Multicultural Development, 1-7.

[12] Goddard, A. 2001. The Language of Advertising: Written texts (2nd ed.). London: Routledge.
[13] Gorter, D., and J. Cenoz. 2008. Knowledge about Language and Linguistic Landscape." In Encyclopedia of Language and Education, edited by N. H. Hornberger (2nd ed), 343-355. New York, NY: Springer.

[14] Griffin, J. L. 2004. The presence of written English on the streets of Rome. English Today, 20 (2), 3-7 \&47.

[15] Kress, G., and T. Van Leeuwen. 1998. "The Critical Analysis of Newspaper Layout." In Approaches to Media Discourse, edited by A. Bell, and P. Garrett, 86-219. Oxford: Blackwell.

[16] Landry, R., and R. Y. Bourhis. 1997. "Linguistic Landscape and Ethnolinguistic Vitality: An Empirical Study." Journal of Language and Social Psychology 16 (1): 23-49.

[17] Magdalena K. 2020. Linguistic landscape in a city of migrants: a study of Souk Naif area in Dubai, International Journal of Multilingualism. DOI: 10.1080/14790718.2020.1781132

[18] MacGregor, L. 2003. The language of shop signs in Tokyo. English Today 19 (1): 18-23.

[19] Reh, M. 2004. "Multilingual Writing: A Reader-oriented Typology-with Examples from Lisa Municipality (Uganda)." International Journal of the Sociology of Language 170: 1-41.

[20] Schlick, M. 2003. The English of shop signs in Europe. English Today 19 (1): 3-17.

[21] Scollon, R., and S. W. Scollon. 2003. Discourses in Place: Language in the Material World. London, UK: Routledge.

[22] Shohamy, E., and D. Gorter. 2009. Linguistic Landscape: Expanding the Scenery. New York, NY: Routledge.

[23] Spolsky, B. 2007. "Forword by Bernard Spolsky." In Linguistic Landscapes: A Comparative Study of Urban Multilingualism in Tokyo, edited by P. Backhaus, ix-x. Clevedon, UK: Multilingual Matters.

[24] Shang, G. W. 2021. Multilingualism in the linguistic landscape of Eastern China: City residents' perceptions and attitudes. Globe: A Journal of Language, Culture and Communication, 12:99-116.

[25] Yao, X., and Gruba, P. 2020. A layered investigation of Chinese in the linguistic landscape: A case study of Box Hill, Melbourne. Australian Review of Applied Linguistics, 43(3): 302-336. 